\title{
Overexpression of C10orf116 promotes proliferation, inhibits apoptosis and enhances glucose transport in 3T3-L1 adipocytes
}

\author{
LING CHEN $^{1 *}$, XIAO-GUANG ZHOU ${ }^{2 *}$, XIAO-YU ZHOU ${ }^{2}$, CHUN ZHU $^{1}$, CHEN-BO JI $^{1}$, \\ CHUN-MEI SHI ${ }^{3}$, JIE QIU ${ }^{2}$ and XI-RONG GUO ${ }^{1,3}$
}

\author{
${ }^{1}$ Department of Pediatrics, Nanjing Maternity and Child Health Hospital of Nanjing Medical University, Nanjing, \\ Jiangsu $210004 ;{ }^{2}$ Department of Newborn Infants, Nanjing Children's Hospital of Nanjing Medical University, Nanjing, \\ Jiangsu 210008; ${ }^{3}$ Institute of Pediatrics of Nanjing Medical University, Nanjing, Jiangsu 210029, P.R. China
}

Received December 22, 2012; Accepted February 27, 2013

DOI: $10.3892 / \mathrm{mmr} .2013 .1351$

\begin{abstract}
Data from our previous study demonstrated that C10orf116 is an adipocyte lineage-specific nuclear factor, which regulates master adipogenesis transcription factors during early differentiation. However, the precise functional properties of this gene have yet to be identified and further investigation is required. In the present study, we report the effects of C10orf116 expression on cell proliferation and apoptosis in vitro and observed that the overexpression of C10orf116 stimulates proliferation and inhibits apoptosis in preadipocytes. Furthermore, we investigated the effects of C10orf116 on glucose uptake and demonstrated that the ectopic expression of C10orf116 significantly increases insulin-stimulated glucose uptake in adipocytes by increasing glucose transporter type 4 (GLUT4) expression levels. Collectively, these data further support the hypothesis that C10orf116 is important in regulating glucose transport in adipocytes as well as the number of preadipocytes. The results of the present study may also provide insights into the complex mechanisms involved in the development of obesity.
\end{abstract}

\section{Introduction}

Obesity results from the interaction between genetic, environmental and psychosocial factors. Obesity poses an important

Correspondence to: Dr Jie Qiu, Department of Newborn Infants, Nanjing Children's Hospital of Nanjing Medical University, 72 Guangzhou Road, Nanjing, Jiangsu 210008, P.R. China

E-mail: jieqiu@yahoo.cn

Professor Xi-Rong Guo, Department of Pediatrics, Nanjing Maternity and Child Health Hospital of Nanjing Medical University, No. 123 Tianfei Xiang, Mochou Road, Nanjing, Jiangsu 210004, P.R. China E-mail:xrguo@njmu.edu.cn

\section{*Contributed equally}

Key words: obesity, adipocyte, proliferation, apoptosis, glucose transport public health issue in the developed world and a growing health issue in the developing world. The current worldwide epidemic of obesity, along with its implications for public health, emphasizes the importance of understanding the complex mechanisms implicated in its development. Although $>600$ genes, markers and chromosomal regions have been identified to be associated with or linked to human obesity phenotypes (1), the responsible genes remain unknown in $>95 \%$ of severe obesity cases (2). Thus, identification of novel genes and proteins associated with the development of obesity remains an important issue.

Data from our previous study (3) demonstrated that Cl0orf116 is highly expressed in adipose tissue and is localized primarily within the nucleus. Overexpression studies in 3T3-L1 cells indicated that C10orf116 upregulated the transcription levels of CCAAT-enhancer-binding protein (C/EBP) $\alpha$ and peroxisome proliferator-activated receptor (PPAR) $\gamma$, and promoted adipogenic differentiation during the early stages of adipogenesis. However, more precise functional properties of this gene need to be clarified and require further investigation.

In the present study, we report on the effects of C10orf116 on cell proliferation and apoptosis in vitro. Our results indicate that the overexpression of C10orf116 in preadipocytes stimulates proliferation and inhibits apoptosis. Furthermore, we investigated the effects of C10orf116 on glucose uptake and demonstrated that the ectopic expression of C10orf116 significantly increases insulin-stimulated glucose uptake in adipocytes by increasing glucose transporter type 4 (GLUT4) expression levels.

\section{Materials and methods}

Cell culture and differentiation. 3T3-L1 preadipocytes [American Type Culture Collection (ATCC), Manassas, VA, USA] were maintained in Dulbecco's medified Eagle's medium (DMEM) supplemented with 10\% fetal calf serum (FCS) (Biomedia, Boussens, France), $100 \mathrm{U} / \mathrm{ml}$ penicillin and $50 \mu \mathrm{g} / \mathrm{ml}$ streptomycin (Invitrogen, Life technologies, Carlsbad, CA, USA) at $37^{\circ} \mathrm{C}$ in $5 \% \mathrm{CO}_{2}$. The 3T3-L1 cells that were stably integrated into either the pcDNA3.1Myc/HisBC10orf116 plasmid or the empty vector were established as previously described (3). To induce differentiation, 2-day 
post-confluent 3T3-L1 preadipocytes (day 0) were exposed to differentiation cocktail $(100 \mu \mathrm{M}$ methylisobutylxanthine, $0.25 \mu \mathrm{M}$ dexamethasone and $1 \mu \mathrm{g} / \mathrm{ml}$ insulin). Two days later (day 2), cells were switched to medium containing $1 \mu \mathrm{g} / \mathrm{ml}$ insulin for 2 days (day 4). The cells were then switched back to DMEM containing only $10 \%$ FCS until day 8 . Cultures were replenished every 2 days.

3-(4,5-Dimethylthiazol-2-yl)-2,5-diphenyltetrazolium bromide (MTT) assay. Adipocytes $\left(2 \times 10^{2}\right.$ cells/well) were seeded in 96-well culture plates and maintained in serum-free DMEM for $24 \mathrm{~h}$ until they were adherent. The cells were then cultured in DMEM supplemented with $10 \%$ FCS. Cell growth was monitored for 7 days successively using the Cell Proliferation MTT kit (Roche Diagnostics GmbH, Mannheim, Germany) according to the manufacturer's instructions. Following this, $10 \mu \mathrm{l}$ of MTT labeling reagent were added to each well and incubated for $4 \mathrm{~h}$ at $37^{\circ} \mathrm{C}$. Solubilization solution $(100 \mu \mathrm{l})$ was then added to each well and cells were incubated overnight. The absorbance values at 560 and $660 \mathrm{~nm}$ were recorded by an ELISA reader and the difference between these values was recorded as the optical density (OD).

Cell cycle assay. Cells were incubated at a density of $2 \times 10^{6}$ cells $/ 750 \mathrm{~mm}^{2}$ in DMEM supplemented with $10 \%$ FCS, then washed with PBS and starved in serum-free DMEM for $24 \mathrm{~h}$ for synchronization. The cell cycle was initiated by replacement of the starvation medium with full medium (DMEM with $10 \% \mathrm{FCS})$ at various time points $(0$, $6,12,18,24 \mathrm{~h}$ ) following serum deprivation. Cultured cells were harvested using trypsin/EDTA and washed twice with PBS. Aliquots of $2 \times 10^{6}$ cells were centrifuged, fixed in $70 \%$ ethanol and stained with $500 \mu \mathrm{l}$ propidium iodide (PI) solution $(100 \mu \mathrm{g} / \mathrm{ml}$ RNase and $50 \mu \mathrm{g} / \mathrm{ml}$ PI in 1X PBS). Labeled cells were analyzed using a BD FACScan (BD Biosciences, Franklin Lakes, NJ, USA) and data were analyzed using CellQuest software (BD Biosciences).

Evaluation of apoptotic index. Cells were cultured in FCS-free DMEM for $24 \mathrm{~h}$ to induce apoptosis. Cells were then harvested using trypsin/EDTA, washed with PBS, resuspended in $1 \mathrm{ml}$ of binding buffer and stained with $10 \mu \mathrm{l}$ fluorescein isothiocyanate (FITC)-labeled Annexin V and $10 \mu \mathrm{l} \mathrm{PI}$ at room temperature for 5 min (BioVision, Mountain View, CA, USA). The fluorescence of FITC and PI was analyzed by flow cytometry.

Hoechst 33342 staining. Following the induction of apoptosis, cells were treated with the apoptosis Hoechst 33324 staining kit (Sigma, St. Louis, MO, USA) for 5-10 min according to the manufacturer's instructions. The cells were incubated with phenol red-free Hanks' balanced salt solution containing $3 \mu \mathrm{M}$ of Hoechst 33342 and washed with PBS twice. Images were observed under a fluorescence microscope.

Caspase-3 and -8 activity. Following the induction of apoptosis, cells were collected and washed with PBS. The activity of caspase-3 and -8 was assayed using commercially available kits (Sigma) according to the manufacturer's instructions. The measurements were based on the hydrolysis of acetyl-Asp-GluVal-Asp p-nitroanilide (Ac-DEVD-pNA). The reaction results in the release of the p-nitroaniline (pNA) moiety. The pNA moiety was detected spectrophotometrically at $405 \mathrm{~nm}$. The concentration of pNA released from the substrate was calculated from a calibration curve prepared with pNA standards. In order to confirm the measurements, additional experiments using adequate inhibitors included in the kit were performed.

Glucose uptake. 2-Deoxy-D-[ $\left[{ }^{3} \mathrm{H}\right]$ glucose (CIC, Beijing, China) uptake was assayed as previously described (4). The cells were cultured in 6-well plates and were serum starved in DMEM containing $0.5 \%$ FCS for $3 \mathrm{~h}$ prior to the experiments. The cells were then washed twice with PBS and incubated in KRP-HEPES buffer [30 mmol/1 HEPES (pH 7.4), $10 \mathrm{mmol} / 1$ $\mathrm{NaHCO}_{3}, 120 \mathrm{mmol} / \mathrm{l} \mathrm{NaCl}, 4 \mathrm{mmol} / \mathrm{K} \mathrm{KH}_{2} \mathrm{PO}_{4}, 1 \mathrm{mmol} / \mathrm{l}$ $\mathrm{MgSO}_{4}$ and $\left.1 \mathrm{mmol} / 1 \mathrm{CaCl}_{2}\right]$ in the presence or absence of $100 \mathrm{nmol} / 1$ insulin for $30 \mathrm{~min}$ at $37^{\circ} \mathrm{C}$. Labeled 2-deoxy$D-\left[{ }^{3} \mathrm{H}\right]$ glucose was added to a final concentration of $2 \mu \mathrm{Ci} / \mathrm{ml}$. After $10 \mathrm{~min}$ at $37^{\circ} \mathrm{C}$, the reaction was terminated by washing with ice-cold PBS 3 times, supplemented with $10 \mathrm{mmol} / \mathrm{l}$ $D$-glucose. The cells were solubilized by adding $200 \mu \mathrm{l}$ of $1 \mathrm{~mol} / \mathrm{l} \mathrm{NaOH}$ to each well and aliquots of the cell lysate were transferred to scintillation vials for radioactivity counting; the remainder was used for the protein assay.

GLUT4 expression. Total RNA was extracted from 3T3-L1 adipocytes using TRIzol reagent (Invitrogen Life Technologies) and the extracted RNA was quantified by spectrophotometry at $260 \mathrm{~nm}$. cDNA was synthesized from $1 \mu \mathrm{g}$ of total RNA by using an AMV Reverse Transcriptase kit (Promega A3500; Promega Corp., Madison, WI, USA) according to the manufacturer's instructions. Real-time RT-PCR was performed using the TaqMan Sequence Detection System and the DNA double-strand-specific SYBR-Green I dye (Roche Diagnostics $\mathrm{GmbH}$ ) according to the manufacturer's instructions. The samples were briefly incubated at $95^{\circ} \mathrm{C}$ for $10 \mathrm{~min}$ for an initial denaturation, followed by 40 PCR cycles. Each cycle consisted of incubation at $95^{\circ} \mathrm{C}$ for $15 \mathrm{sec}$ and $60^{\circ} \mathrm{C}$ for $1 \mathrm{~min}$. We used $\beta$-actin as the reference in a comparative CT method and obtained the relative changes in the target samples. We used the following primers for the PCR analyses: GLUT4 homologous genes in mouse forward, 5'-ATT GGA CGC TCT CTC TCC AA-3' and reverse, 5'-GAT TCT GCT GCC CTT CTGTC-3'; and $\beta$-actin forward, 5'-ATC TGG CAC CAC ACC TTC-3' and reverse, 5'-AGC CAG GTC CAG ACG CA-3'.

Statistical analysis. All data are expressed as the means \pm SEM. Statistical analysis was performed using the paired Student's t-test using the SPSS 10.0 statistical software package (SPSS, Inc., Chicago, IL, USA). P $<0.05$ was considered to indicate a statistically significant difference.

\section{Results}

Effects of C10orf116 on cell proliferation. As indicated by MTT assay (Fig. 1), the overexpression of C10orf116 in 3T3-L1 preadipocytes resulted in a significantly higher rate of proliferation compared with the cells transfected with the empty vector at each time point. C10orf116 also had an effect on the cell cycle. The percentage of 3T3-L1 cells overexpressing C10orf116 in the S phase was significantly higher compared 


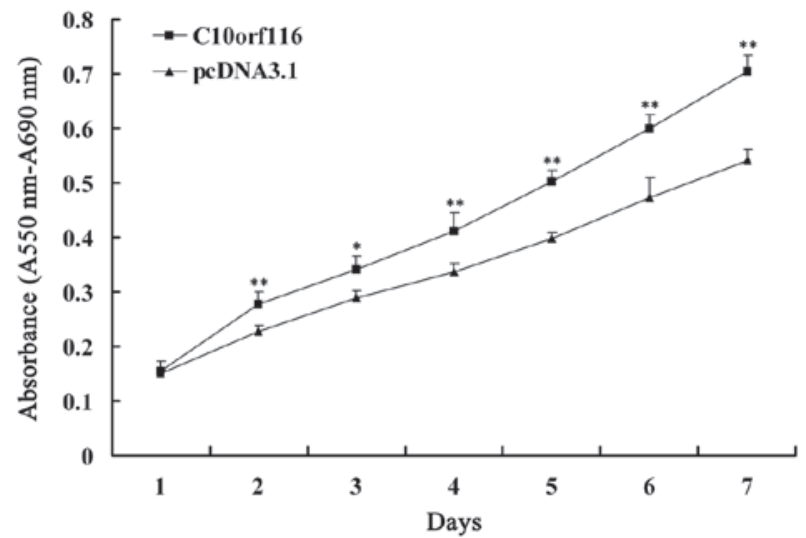

Figure 1. MTT assay. Adipocytes $\left(2 \times 10^{2}\right.$ cells/well) were seeded in 96-well culture plates and maintained in serum-free DMEM for $24 \mathrm{~h}$ until they were adherent, after which they were cultured in DMEM supplemented with $10 \%$ FCS. Cell growth was monitored by MTT assay for 7 days successively. The absorbance values at 560 and $660 \mathrm{~nm}$ were recorded by an ELISA reader and the difference between these values was recorded as the optical density (OD). The results showed that preadipocytes overexpressing C10orf116 had an increased growth rate compared with the control cells transfected with the empty vector. Data are presented as the means \pm SEM of a triplicate experiment. ${ }^{*} \mathrm{P}<0.05,{ }^{* *} \mathrm{P}<0.01$. FCS, fetal calf serum; MTT, 3-(4,5-dimethylthiazol-2-yl)-2,5-diphenyltetrazolium bromide.

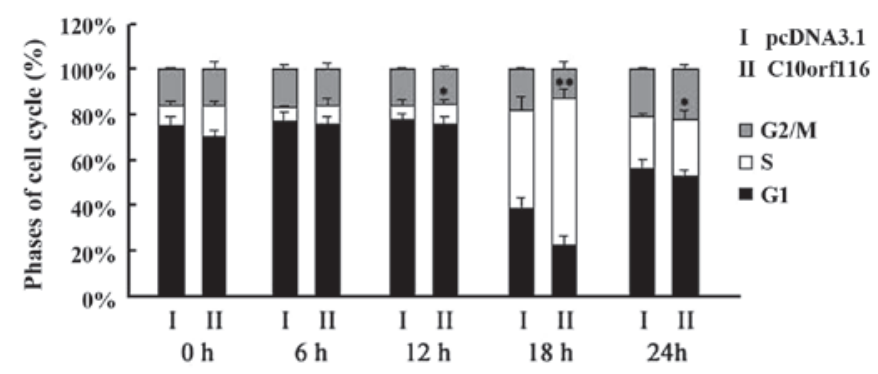

Figure 2. Cell cycle assay. Cells were starved in serum-free DMEM for $24 \mathrm{~h}$ for synchronization. The cell cycle was initiated by replacement with full medium at various time points $(0,6,12,18$ and $24 \mathrm{~h})$ following serum deprivation. Cells were stained with $500 \mu \mathrm{l}$ PI solution and were analyzed using a BD FACScan. The data showed that the percentage of 3T3-L1 cells overexpressing C10orf116 in the S phase was significantly higher compared to the control cells upon replacement of starvation medium with full medium at 12, 18 and $24 \mathrm{~h}$ following serum deprivation. Data are presented as the means \pm SEM of a triplicate experiment. ${ }^{*} \mathrm{P}<0.05,{ }^{* *} \mathrm{P}<0.01$. $\mathrm{PI}$, propidium iodide.

to the control cells following the replacement of the starvation medium with full medium at 12,18 and $24 \mathrm{~h}$ and following serum deprivation, as shown by flow cytometry (Fig. 2).

Effects of C10orf116 on cell apoptosis. Annexin V was shown to interact strongly and specifically with phosphatidylserine and may be used to detect the early stages of apoptosis by targeting the loss of plasma membrane asymmetry (5). To examine the effects of C10orf116 on cell apoptosis, cells were cultured in FCS-free DMEM for $24 \mathrm{~h}$ to induce apoptosis and the apoptotic index was analyzed. As shown in Fig. 3, C10orf116 protects 3T3-L1 preadipocytes from serum deprivation-induced apoptosis. In addition, the results of the Hoechst 33342 staining demonstrated that the 3T3-L1 cells transfected with the pcDNA.3.1 vector exhibited more significant apoptotic morpho-

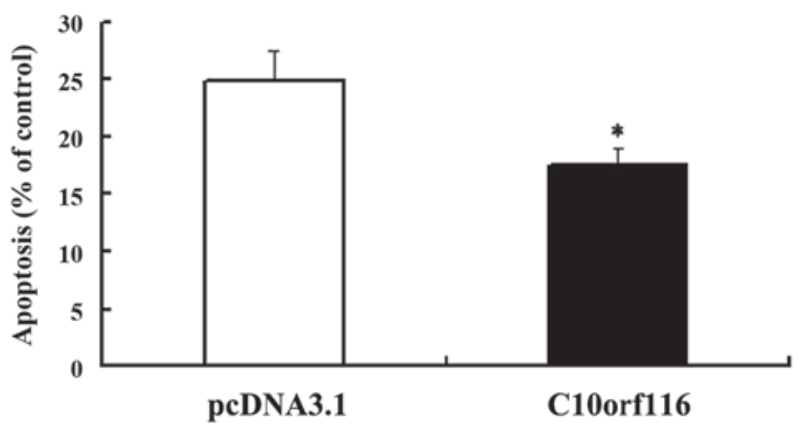

Figure 3. Evaluation of the apoptotic index. Cells were cultured in FCSfree DMEM for $24 \mathrm{~h}$ to induce apoptosis and were then stained with $10 \mu \mathrm{l}$ Annexin V-FITC and $10 \mu \mathrm{l}$ PI at room temperature for $5 \mathrm{~min}$. The fluorescence of FITC and PI was analyzed by flow cytometry. The data demonstrated that the apoptotic index of 3T3-L1 cells overexpressing C10orf116 was significantly lower compared to the control cells. Data are presented as the means \pm SEM of a triplicate experiment. ${ }^{*} \mathrm{P}<0.05$. PI, propidium iodide; FCS, fetal calf serum.

logical changes, including chromatin condensation and the formation of apoptotic bodies (Fig. 4C) compared with the cells transfected with the C10orf116-pcDNA3.1 vector (Fig. 4D). However, no significant differences were observed in the control cells (Fig. 4A) and the cells overexpressing C10orf116 without the induction of apoptosis (Fig. 4B). Caspase-3 and -8 activity was also determined. The data (Fig. 5) also showed that 3T3-L1 preadipocytes transfected with the C10orf116-pcDNA3.1 vector had a lower caspase- 3 and -8 activity compared with the cells transfected with the pcDNA.3.1 vector. These results indicate that C10orf116 inhibits apoptosis in preadipocytes induced by serum deprivation.

Effects of C10orf116 on basal and insulin-stimulated glucose uptake and GLUT4 expression. The transfected 3T3-L1 preadipocytes were induced to differentiate as described in Materials and methods. Glucose uptake was then assayed in the 3T3-L1 adipocytes with or without C10orf116 overexpression. As shown in Fig. 6, the insulin-stimulated glucose uptake was significantly enhanced in the adipocytes overexpressing C10orf116; however, the basal glucose uptake was similar compared with the control cells. In the adipocytes, insulinstimulated glucose uptake is dependent on the expression, the activity or the translocation of the insulin-responsive glucose transporter GLUT4 (6-10). Therefore, we further examined the effects of C10orf116 on GLUT4 expression during the differentiation of 3T3-L1 preadipocytes. The results demonstrated that C10orf116 overexpression significantly increased GLUT4 expression on days 4 and 8 of differentiation (Fig. 7).

\section{Discussion}

Obesity is an increasing global health issue that is usually accompanied by a number of serious health impairments, including type 2 diabetes and cardiovascular disease (11). Considerable evidence suggests that obesity is caused by the interaction between multiple genes and the environment $(12,13)$. A better understanding of the candidate genes required for the development of obesity may form the basis for novel therapies that directly target the molecular mechanisms 
A

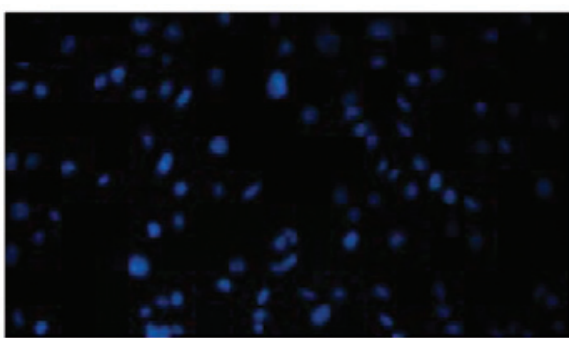

C

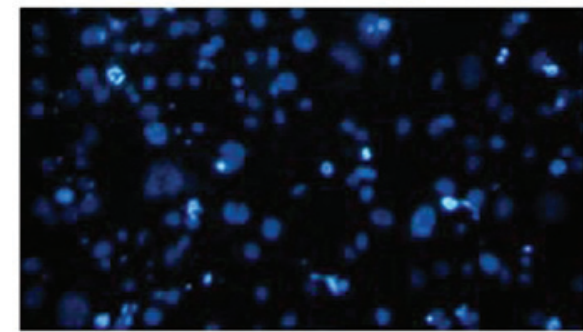

B

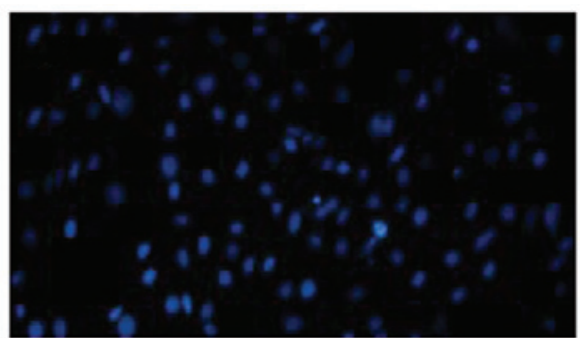

D

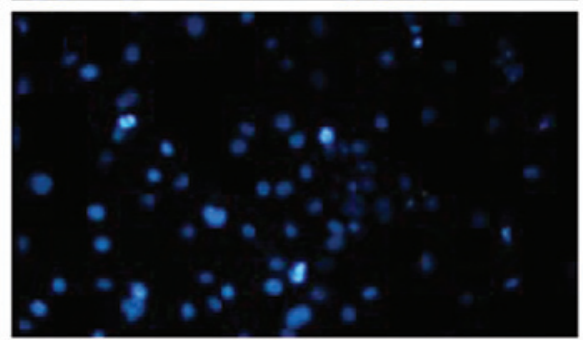

Figure 4. Hoechst 33342 staining. Following the induction of apoptosis, cells were treated with the apoptosis Hoechst 33324 staining kit for 5-10 min according to the manufacturer's instructions and washed with PBS twice. Images were observed under a fluorescence microscope. (C) The results demonstrated that the control cells exhibited more evident apoptotic morphological changes, such as chromatin condensation and the formation of apoptotic bodies compared to the (D) 3T3-L1 cells overexpressing C10orf116. However, there were no significant differences observed between (A) the control cells without the induction of apoptosis and (B) in the cells overexpressing C10orf116 without the induction of apoptosis.

A

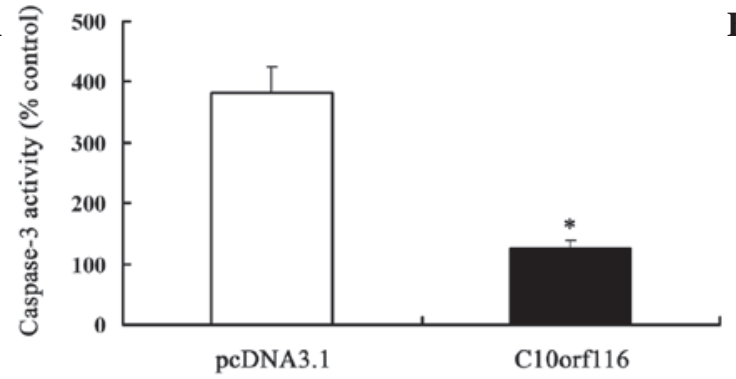

B

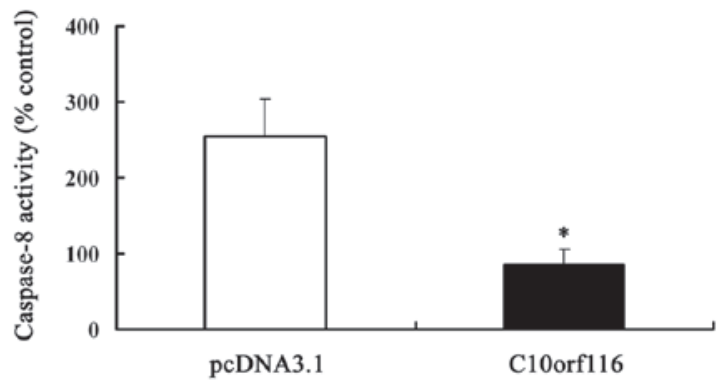

Figure 5. Caspase-3 and -8 activity. Following the induction of apoptosis, cells were collected and washed with PBS. The activity of caspase- 3 and -8 was assayed using commercially available kits based on the hydrolysis of acetyl-Asp-Glu-Val-Asp p-nitroanilide (Ac-DEVD-pNA). The data showed that 3T3-L1 cells overexpressing C10orf116 had a lower (A) caspase-3 and (B) caspase-8 activity compared with the control cells. Data are represented as the means \pm SEM of a triplicate experiment. ${ }^{*} \mathrm{P}<0.05$.

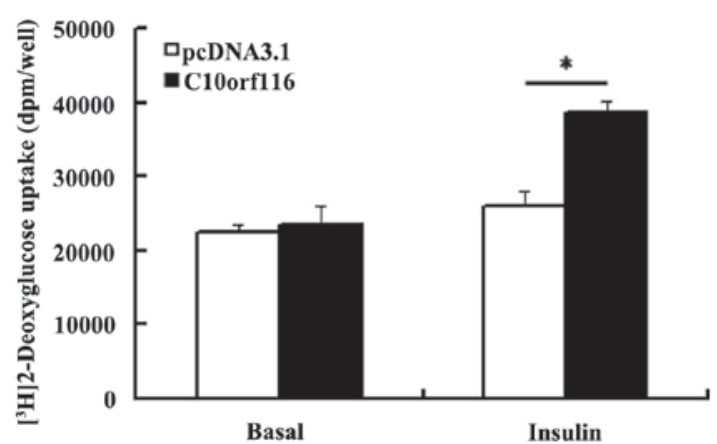

Figure 6. Glucose uptake. The cells were serum starved in DMEM containing $0.5 \% \mathrm{FCS}$ for $3 \mathrm{~h}$ and then washed twice with PBS. The cells were incubated in KRP-HEPES buffer in the presence or absence of $100 \mathrm{nmol} / \mathrm{l}$ insulin for 30 min at $37^{\circ} \mathrm{C}$. Labeled 2-deoxy- $D-\left[{ }^{3} \mathrm{H}\right]$ glucose was added to a final concentration of $2 \mu \mathrm{Ci} / \mathrm{ml}$ for $10 \mathrm{~min}$ at $37^{\circ} \mathrm{C}$ and was terminated by washing with ice-cold PBS 3 times, supplemented with $10 \mathrm{mmol} / 1 \mathrm{D}$-glucose. The cells were solubilized in $1 \mathrm{~mol} / 1 \mathrm{NaOH}$ and transferred to scintillation vials for radioactivity counting. The data demonstrated that insulin-stimulated glucose uptake was significantly enhanced in the 3T3-L1 cells overexpressing C10orf116; however, the basal glucose uptake was similar compared with the control cells. Data are presented as the means \pm SEM of a triplicate experiment. ${ }^{*} \mathrm{P}<0.05$. FCS, fetal calf serum; DPM, disintegrations per minute.

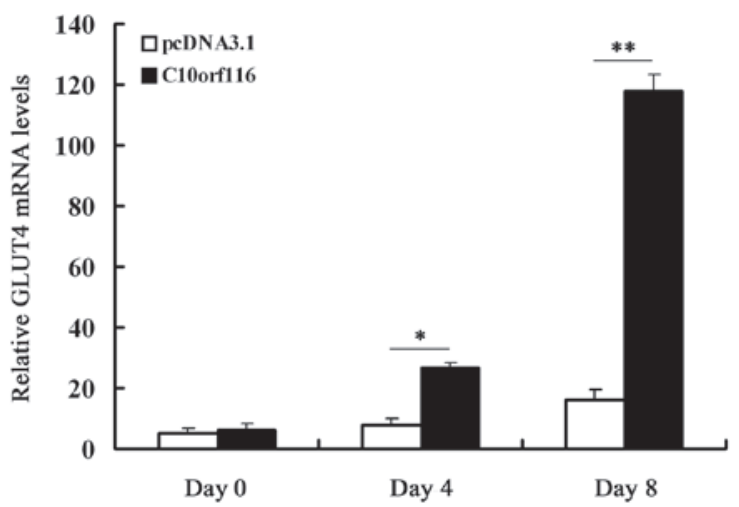

Figure 7. GLUT4 expression. Two-day post-confluent 3T3-L1 preadipocytes (day 0 ) were exposed to the differentiation cocktail. Two days later (day 2), cells were switched to medium containing $1 \mu \mathrm{g} / \mathrm{ml}$ insulin for 2 days (day 4). The cells were then switched back to DMEM containing only 10\% FCS until day 8 . The cells were collected on days 0,4 and 8 . GLUT4 mRNA expression levels relative to $\beta$-actin were examined by real-time RT-PCR. The data demonstarted that GLUT4 expression in 3T3-L1 cells overexpressing C10orf116 was significantly higher compared to the control cells on days 4 and 8 of differentiation. Data are presented as the means \pm SEM of a triplicate experiment. ${ }^{*} \mathrm{P}<0.05,{ }^{* *} \mathrm{P}<0.01$. FCS, fetal calf serum. 
underlying obesity. In our previous study (3), we identified C10orf116 as a novel gene that may be important in the development of obesity. Overexpression studies in 3T3-L1 cells indicated that C10orf116 upregulated the transcription levels of $\mathrm{C} / \mathrm{EBP} \alpha$ and PPAR $\gamma$, and promoted adipogenic differentiation beginning from the early stage of adipogenesis. In the present study, we further investigated the association between C10orf116 and obesity.

As a metabolic and endocrine organ, adipose tissue is important in the regulation of energy balance (14). Accordingly, adipocytes are emerging as a potential therapeutic target for obesity, type 2 diabetes and cardiovascular disease (15). Adipose tissue mass reflects the number and average volume of adipocytes, in particular the balance between cell acquisition and cell loss (16-18). The proliferation of adipocyte precursors and their differentiation into mature adipocytes contribute to the development of obesity in mammals. Apoptosis is another important mechanism regulating adipose tissue mass (19-22). Therefore, we further investigated the effects of C10orf116 on 3T3-L1 preadipocyte proliferation and apoptosis by establishing a stably transfected 3T3-L1 cell line overexpressing C10orf116 and demonstrated that: i) C10orf116 causes the promotion of cell population growth in 3T3-L1 preadipocytes indicated by results of MTT assay, and cell cycle analysis by flow cytometry showed a significantly increased percentage of cells in the S phase in C10orf116-overexpressing preadipocytes; ii) cell apoptosis analysis by Annexin V-FITC, Hoechst 33342 , caspase-3 and -8 activity demonstrated that C10orf116 may prevent apoptosis induced by serum deprivation. In conclusion, our data demonstrate that by increasing cell proliferation and lowering the apoptotic rate, C10orf116 may affect the size of the preadipocyte pool and influence adipose tissue homeostasis. The function and mechanism of C10orf116 in adipocytes requires further investigation.

In adipocytes, insulin plays a role in multiple stages of glucose metabolism. One of its most important effects is the ability to increase the rate of cellular glucose transport (23). In this study, we observed that C10orf116 overexpression significantly increases insulin-stimulated glucose transport in mature adipocytes and exerted no effect on basal glucose uptake. We examined GLUT4 expression to determine the mechanism by which C10orf116 increases insulin-stimulated glucose uptake. The results indicated that C10orf116 affected insulin-stimulated glucose uptake by increasing GLUT4 expression levels.

Collectively, these data further support the hypothesis that C10orf116 is important in regulating the number of preadipocytes and glucose transport in adipocytes and aids in the understanding of the complex mechanisms responsible for obesity. However, in vivo research is required to verify the physiological functions of this gene. Future studies addressing the biochemical and functional properties of C10orf116 may provide further insight into its role in obesity.

\section{Acknowledgements}

This study was supported by grants from the National Key Basic Research Program of China (2013CB530604), the National Natural Science Foundation of China (no. 81000349) and the Science and Technology Development Fund of Nanjing Medical University (09njmum052).

\section{References}

1. Pérusse L, Rankinen T, Zuberi A, et al: The human obesity gene map: the 2004 update. Obes Res 13: 381-490, 2005.

2. Flier JS: Obesity wars: molecular progress confronts an expanding epidemic. Cell 116: 337-350, 2004.

3. Ni Y, Ji C, Wang B, Qiu J, Wang J and Guo X: A Novel pro-adipogenesis factor abundant in adipose tissues and over-expressed in obesity acts upstream of PPAR $\gamma$ and $\mathrm{C} / \mathrm{EBP} \alpha$. J Bioenerg Biomembr: Dec 13, 2012 (Epub ahead of print).

4. Ceddia RB, Somwar R, Maida A, Fang X, Bikopoulos G and Sweeney G: Globular adiponectin increases GLUT4 translocation and glucose uptake but reduces glycogen synthesis in rat skeletal muscle cells. Diabetologia 48: 132-139, 2005.

5. Vermes I, Haanen C, Steffens-Nakken H and Reutelingsperger C: A novel assay for apoptosis. Flow cytometric detection of phosphatidylserine expression on early apoptotic cells using fluorescein labelled Annexin V. J Immunol Methods 184: 39-51, 1995.

6. Bryant NJ, Govers R and James DE: Regulated transport of the glucose transporter GLUT4. Nat Rev Mol Cell Biol 3: 267-277, 2002.

7. Kanzaki M: Insulin receptor signals regulating GLUT4 translocation and actin dynamics. Endocr J 53: 267-293, 2006.

8. Tozzo E, Gnudi L and Kahn BB: Amelioration of insulin resistance in streptozotocin diabetic mice by transgenic overexpression of GLUT4 driven by an adipose-specific promoter. Endocrinology 138: 1604-1611, 1997.

9. Garvey WT, Hardin D, Juhaszova M and Dominguez JH: Effects of diabetes on myocardial glucose transport system in rats: implications for diabetic cardiomyopathy. Am J Physiol 264: H837-H844, 1993.

10. Park SY and Lee W: The depletion of cellular mitochondrial DNA causes insulin resistance through the alteration of insulin receptor substrate-1 in rat myocytes. Diabetes Res Clin Pract 77 (Suppl 1): S165-S171, 2007.

11. Mokdad AH, Ford ES, Bowman BA, et al: Prevalence of obesity, diabetes, and obesity-related health risk factors, 2001. JAMA 289: 76-79, 2003.

12. Lee YS: The role of genes in the current obesity epidemic. Ann Acad Med Singapore 38: 45-43, 2009.

13. Walley AJ, Asher JE and Froguel P: The genetic contribution to non-syndromic human obesity. Nat Rev Genet 10: 431-442, 2009.

14. Rosen ED and Spiegelman BM: Adipocytes as regulators of energy balance and glucose homeostasis. Nature 444: 847-853, 2006.

15. Nawrocki AR and Scherer PE: Keynote review: the adipocyte as a drug discovery target. Drug Discov Today 10: 1219-1230, 2005.

16. Furuyashiki T, Nagayasu H, Aoki Y, et al: Tea catechin suppresses adipocyte differentiation accompanied by downregulation of PPARgamma2 and C/EBPalpha in 3T3-L1 cells. Biosci Biotechnol Biochem 68: 2353-2359, 2004.

17. Brook CG, Lloyd JK and Wolf OH: Relation between age of onset of obesity and size and number of adipose cells. Br Med J 2: 25-27, 1972 .

18. Prins JB and O'Rahilly S: Regulation of adipose cell number in man. Clin Sci (Lond) 92: 3-11, 1997.

19. Sorisky A, Magun R and Gagnon AM: Adipose cell apoptosis: death in the energy depot. Int J Obes Relat Metab Disord 24 Suppl 4: S3-S7, 2000.

20. Della-Fera MA, Qian H and Baile CA: Adipocyte apoptosis in the regulation of body fat mass by leptin. Diabetes Obes Metab 3: 299-310, 2001.

21. Margareto J, Aguado M, Osés-Prieto JA, et al: A new NPY-antagonist strongly stimulates apoptosis and lipolysis on white adipocytes in an obesity model. Life Sci 68: 99-107, 2000.

22. Della-Fera MA, Li C and Baile CA: Resistance to IP leptininduced adipose apoptosis caused by high-fat diet in mice. Biochem Biophys Res Commun 303: 1053-1057, 2003.

23. Ducluzeau PH, Fletcher LM, Vidal H, Laville M and Tavaré JM: Molecular mechanisms of insulin-stimulated glucose uptake in adipocytes. Diabetes Metab 28: 85-92, 2002. 